\title{
Attitudes, norms, identity and environmental behaviour: Using an expanded theory of planned behaviour to predict participation in a kerbside recycling programme ${ }^{1}$
}

Dennis Nigbur, Canterbury Christ Church University

Evanthia Lyons, Queen's University Belfast

David Uzzell, University of Surrey

\author{
Address for correspondence: \\ Dr Dennis Nigbur \\ Lecturer in Psychology \\ Department of Applied Social Sciences \\ Canterbury Christ Church University \\ Canterbury, Kent CT1 1QU \\ United Kingdom. \\ Tel. +44 (0)1227 767700 x3838 \\ email dennis.nigbur@ canterbury.ac.uk
}

Running Head: Attitudes, norms, identity

\footnotetext{
${ }^{1}$ Nigbur, D., Lyons, E., and Uzzell, D. (2010). Attitudes, norms, identity and environmental behaviour: Using an expanded theory of planned behaviour to predict participation in a kerbside recycling programme, British Journal of Social Psychology,49, 2, 259-284
} 


\begin{abstract}
In an effort to contribute to greater understanding of norms and identity in the theory of planned behaviour, an extended model was used to predict residential kerbside recycling, with self-identity, personal norms, neighbourhood identification and injunctive and descriptive social norms as additional predictors. Data from a field study $(N=527)$ using questionnaire measures of predictor variables and an observational measure of recycling behaviour supported the theory. Intentions predicted behaviour, while attitudes, perceived control, and the personal norm predicted intention to recycle. The interaction between neighbourhood identification and injunctive social norms in turn predicted personal norms. Self-identity and the descriptive social norm significantly added to the original theory in predicting intentions as well as behaviour directly. A replication survey on the self-reported recycling behaviours of a random residential sample $(N=264)$ supported the model obtained previously. These findings offer a useful extension of the theory of planned behaviour and some practicable suggestions for pro-recycling interventions. It may be productive to appeal to self-identity by making people feel like recyclers, and to stimulate both injunctive and descriptive norms in the neighbourhood.
\end{abstract}

\title{
Acknowledgements
}

The authors would like to thank Guildford Borough Council, who sponsored the research reported here; Kristopher Preacher for helpfully providing the required SPSS command macros; and three anonymous reviewers for their constructive comments.

Keywords: theory of planned behaviour; norms; environmental behaviour; identity 


\section{Attitudes, norms, identity and environmental behaviour: Using an expanded theory of planned behaviour to predict participation in a kerbside recycling programme}

The theory of planned behaviour (TPB; Ajzen, 1991) and its predecessor, the theory of reasoned action (TRA; Fishbein \& Ajzen, 1975) have had a prominent but somewhat problematic history as a predictive model of behaviour. One shortcoming of the theory - at least from a social-psychological perspective - is its rather individualistic view of human behaviour, which does not explicitly take into account the role of identity and remains underdefined with regard to the functioning of norms. Building on findings from Terry, Hogg and White (1999), the study described here attempts to expand the TPB by elaborating on the social aspects of behaviour, including social and self-identities as well as social and personal norms. Like the study reported by Terry and colleagues, the present work focused on household waste recycling by kerbside collection, where communal interest and visibility give an especially prominent role to the social antecedents of behaviour.

The TPB (Ajzen, 1988, 1991) addresses the oft-observed discrepancy between attitudes and behaviour (for a review, see Ajzen \& Fishbein, 1977) by suggesting that attitude is just one of several determinants of behaviour, and not even its most direct antecedent. Instead, the theory suggests that the intention to engage in a given behaviour is its most proximal predictor. Intention is in turn assumed to be related to attitudes, subjective norm (a sense that one is expected to engage in the behaviour), and perceived behavioural control (the belief that one is able to engage in the behaviour). Attitude thus does not predict behaviour perfectly because it is but one contributor to behavioural intentions, potentially tempered by inconsistent normative or control-related psychological constructs. Moreover, the TPB allows 
for perceived control to affect behaviour directly, regardless of the behavioural intention that is formed. If the individual perceives that she or he lacks the capacity to perform the behaviour, this may override any intention to act.

The efficacy of the TPB has been examined in a thorough meta-analytic review by Armitage and Conner (2001). Data from a total of 185 studies, reported in 161 published articles, were shown to lend general support to the TPB and the relationships stipulated between attitudinal constructs (attitudes, subjective norm and perceived behavioural control), intention and behaviour. However, the authors also identify certain problems with the theory, some of which directly relate to the work reported in the present paper.

First, Armitage and Conner's meta-analysis points to the subjective norm concept as the weakest predictor in the TPB. Whilst some of its problems can be traced to measurement issues and potential differences among target behaviours in their sensitivity to normative influence (see also Ajzen, 1991), Armitage and Conner propose a more radical theoretical reoperationalisation of norms in the TPB. For example, the authors argue that it may be productive to follow Terry et al. (1999) in drawing upon social identity theory (Tajfel \& Turner, 1986) to examine the impact of socially relevant group norms on intentions and behaviour. Also, they suggest that a distinction between injunctive and descriptive norms (Cialdini, Kallgren, \& Reno, 1991; Cialdini, Reno, \& Kallgren, 1990; Kallgren, Reno, \& Cialdini, 2000; Reno, Cialdini, \& Kallgren, 1993) may be of use. Our own studies represent an attempt to incorporate these concepts into the TPB concurrently.

Second, Armitage and Conner show that, for a theory ultimately concerned with the prediction of behaviour, relatively few studies on the TPB actually measure behaviour as a variable. Only about one in ten tests of the theory (19 studies out of the 185 analysed) employed independently rated or observational measures of behaviour, with a similarly modest 44 examining self-reported behaviour. The investigation described here sought to 
assess the utility of the whole TPB model by measuring behaviour observationally (Study 1) or through self-reports (Study 2).

Third, Armitage and Conner point to the success of previous researchers in using a measure of self-identity to explain additional variance in intentions and behaviour. The contribution of such a measure to the prediction of a variety of behaviours is now welldocumented (for reviews, see Conner \& Armitage, 1998; Sparks, 2000; Sparks \& Guthrie, 1998). However, self-identity implications for recycling have only been studied in two published investigations (Mannetti, Pierro, \& Livi, 2004; Terry et al., 1999), and never with an objective measure of behaviour. The present contribution aimed to fill this gap.

In summary, the two studies reported here attempted to address some crucial issues concerning the TPB by offering a more social-psychological perspective on the norm concept and a measure of self-identity to improve the predictive utility of the model in relation to a direct measure of behaviour (observational in Study 1 and self-reported in Study 2). The following sections will describe these additions in detail, with specific reference to the behavioural setting of household waste recycling.

\section{Social and Personal Norms}

Although Ajzen (1991) remains committed to the expectancy-value origins of the $\mathrm{TPB}$, the problematic construct of subjective norm may benefit from an alternative operationalisation, which takes into account the nature and source of normative influence exerted on the individual. Mirroring general concerns about the utility of the subjective norm concept (see Armitage \& Conner, 2001), traditional measures of subjective norm have sometimes been found to predict significantly the intention to recycle (Cheung, Chan, \& Wong, 1999; Steinheider et al., 1999), sometimes not (Boldero, 1995; Terry et al., 1999). To 
refine the theory's account of normative influences on intentions and behaviour, it may thus be instructive, for example, to consider Schwartz's norm activation model (Schwartz, 1977; Schwartz \& Howard, 1980). Summarised briefly, this model postulates that social norms can only become enacted via personal norms. Individuals internalise the normative expectations of the social environment as their own, before they act on them. It stands to reason that social expectations are not absorbed fully by the individual, and that the normative influences on which the individual acts are rather more idiosyncratic (see also Steadman, Rutter, \& Field, 2002). It would therefore appear productive, in the terminology of the TPB, to look at the 'subjective norm' - the individual's sense that she or he is expected to perform a certain behaviour - as a personal norm, in turn influenced by (but not wholly congruent with) social norms. Bratt (1999), for example, found in a study on recycling that there was no direct link between the social norm and behaviour, but that this relationship was mediated by personal norms. The value-belief-norm (VBN) theory (Stern \& Dietz, 1994; Stern, Dietz, Abel, Guagnano, \& Kalof, 1999) makes broadly similar suggestions about the mediation of the relationship between social context and individual action through personal norms; however, given the success of the TPB in explaining conservation-related behaviours even in comparison with the VBN theory (Kaiser, Hübner, \& Bogner, 2005), the studies reported here tried to incorporate the notions of the norm activation model directly into the TPB. It was expected that the personal norm would emerge as a predictor of intention to recycle, and that the relationship between social norms and intention would be at least partly mediated by this personal norm measure.

It is furthermore conceivable that the behavioural impact of social norms could be moderated by identification with the group from which the norm originates, as implied by social identity theory (SIT; Tajfel \& Turner, 1986) and self-categorisation theory (SCT; Turner, Hogg, Oakes, Reicher, \& Wetherell, 1987). Terry et al. (1999) found such a 
moderating effect on the relationship between the neighbourhood norm for recycling and individual intentions to recycle; however, their measures did not include personal norms, which might have played a mediating role. On the other hand, there is also evidence that the relationship between social norms and intentions is not always moderated by identification (Fekadu \& Kraft, 2002), and the argument that norm adherence should increase with group identification is not undisputed (see Turner, 1999). Our work, like that of the aforementioned authors, set the functioning of social norms in affinity to social identity by measuring both the strength of the social norm and identification with the group (here the neighbourhood) from which it stems.

The norm focus theory (e.g. Cialdini et al., 1991), in turn, differentiates between two types of social norms: an injunctive norm (a socially shared rule of conduct) and a descriptive norm (the visible behaviour of others). The injunctive norm is tied to a sanctioning group, whereas the descriptive norm is tied to a location (Reno et al., 1993) - depending on which of these social norms is focal at any one time, the individual will follow a public guideline to behaviour (complying with an injunctive norm) or imitate the actions of others in the setting (complying with a descriptive norm). Applied to household waste recycling, sources of normative influence could therefore be separated into perceptions of whether significant others (the neighbourhood group) would want the individual to recycle, and perceptions of whether others in the neighbourhood actually do recycle themselves.

Whilst the original experimental studies on the norm focus theory examine littering behaviour, it is a new idea to look at injunctive and descriptive social norms about recycling (but see Minton, 1995). With regard to the TPB, an integration of injunctive and/or descriptive social norms into the predictive model has been successfully achieved on the topics of cannabis use (Conner \& McMillan, 1999), contraception (Fekadu \& Kraft, 2002) and the lottery (Sheeran \& Orbell, 1999). In order to examine further the influence of 
injunctive and descriptive social norms, the studies reported in the present paper analysed their contribution to the prediction of personal norms, intentions to recycle and - in the case of descriptive norms, which imply a process of imitation - recycling behaviour, either as linear predictors or in interaction with neighbourhood identification.

\section{Self- or Role-identity}

Stryker's identity theory (Stryker, 1987; Stryker \& Burke, 2000) has been extremely popular as an addition to the TPB, thanks to its capacity to provide a theoretical basis for personal habit and self-involvement. The theory posits that self-identity is made up of a collection of roles fulfilled by the individual (e.g. as a friend, parent, or employee). These roles foster habitual action that contributes to role fulfilment and self-validation. The identityrelevant action or behaviour is maintained over time because the role as an agent of such behaviour is an important part of the individual's self-concept.

The construct of self-identity (or a similar notion of 'role identity') has been widely adopted in the TPB during the past few years (for reviews, see Conner \& Armitage, 1998; Sparks, 2000) and successfully tested in the prediction of intentions relating to exercise (e.g. Theodorakis, 1994), food choices (e.g. Astrom \& Rise, 2001) and contraception (Fekadu \& Kraft, 2001), among many others. In the context of waste recycling, two recent studies (Mannetti et al., 2004; Terry et al., 1999) demonstrated an association of self-identity as a recycler with intentions to participate in recycling. It can therefore be expected that the intention to recycle will, to some degree, be informed by the extent to which the individual 'feels like a recycler', over and above the classic components of the TPB. Also, it is perhaps surprising that direct effects of self-identity on behaviour have seldom been observed (but see Bissonnette \& Contento, 2001; Theodorakis, 1994). Given the conceptual association of self- 
or role-identity with habit, a direct predictive link between self-identity as a recycler and actual recycling behaviour appears a logical hypothesis, which could be tested in our studies thanks to the direct measurement of behaviour.

\section{Predicting Recycling Behaviour}

Following the recommendations of Armitage and Conner (2001), the two studies described below included additional variables (here related to norms and self-identity) in the TPB model to improve the prediction of a direct measure of behaviour (observed participation in kerbside recycling in Study 1, self-reported recycling in Study 2). In line with a large part of the previous literature on the TPB, multiple linear and logistic regression analyses were used to this end. It was tested whether recycling behaviour would be predicted by the constructs suggested by the TPB (intention to recycle and perceived control over recycling) as well as the added predictors of self-identity as a recycler and the behaviour of neighbours (i.e., the descriptive norm).

Intention, in turn, was expected to be predicted by the TPB constructs of attitude and perceived control. Self-identity as a recycler and personal pro-recycling norms (the sense that one ought to recycle) were also hypothesised to contribute to prediction. The relationships between the social norm measures (injunctive and descriptive) and intention were expected to be mediated by personal norms as suggested by the norm activation model. In all analyses involving injunctive or descriptive social norms as predictors, their interaction terms with neighbourhood identification were also tested to try to replicate the social identity approach of Terry et al. (1999). 


\section{STUDY 1}

Our first study was conducted on two recycling collection rounds in largely middleclass districts of Guildford, Surrey (UK), where a council-operated recycling scheme using the "Green Box" for paper, glass and tin recycling served most areas in the Borough with fortnightly kerbside collections. Council estimates of participation at the time of the study were around forty per cent. Our investigation took advantage of a participation monitoring exercise carried out locally to obtain objective, observational measurements of recycling for individual households. Predictor variables were measured by postal questionnaire prior to the start of participation monitoring. The aim of the study was to verify the predictions of the TPB and to assess the impact of additional variables as outlined above.

\section{Method}

\section{Participants and Procedure}

A questionnaire survey about household waste recycling was mailed out to a sample of 1,872 households, which made up two of the recycling collection rounds operated by the Borough Council of Guildford. These two collection rounds were chosen in co-operation with the Borough Council in order to enable participation monitoring for a large number of households and to ensure a reasonable demographic spread. Free-post envelopes addressed to the main researcher were enclosed with the questionnaire to boost the response rate. Also, the instructions drew respondents’ attention to a prize draw for $£ 50$ worth of gift vouchers from local retailers among residents who filled in and returned the questionnaire. A deadline for returns was set for three weeks after the mail-out. 
Towards the date of the deadline, the researcher and an assistant followed the regular council recycling team on their collection rounds in the designated areas and took a manual tally of Green Box set-out for each address; perfect correspondence between the timing of this monitoring exercise and the deadline for the return of surveys was not possible because of the scheduling of collections. Residents were aware that the Borough Council was conducting a participation monitoring exercise in the area, but did not know that this was related to the questionnaire survey.

Of the 1,872 households targeted by the mail-out, 531 returned completed questionnaires, at a response rate of 28.4 per cent. Four respondents claimed not to have been supplied with a Green Box, ${ }^{2}$ and their data are disregarded in the present report. Among the remaining 527 respondents, $325(61.7 \%)$ were female, 185 (35.1\%) male, and $17(3.2 \%)$ declined to provide gender information. The over-61s made up the largest age group, accounting for $28.8 \%$ of the sample. There was satisfactory representation of most other age groups, including 51-60 (19.0\%), 41-50 (19.7\%) and 31-40 (20.1\%), with the 21-30 group $(8.5 \%)$ and especially the under-21s (1.3\%) somewhat under-represented. Thirteen respondents $(2.5 \%)$ did not disclose their age. Full-time employees constituted $38.3 \%$ of participants, with a further $23.7 \%$ working part-time, $33.6 \%$ not in employment (including retired residents and students), and $4.4 \%$ not providing employment information.

Those households who had set out their recycling box on the day of observational measurement appeared to be over-represented among the questionnaire respondents, making up $57.9 \%$ of returns although only $41.2 \%$ of households in the sampling areas had set out their Green Box. A chi-squared analysis on Green Box set-out and questionnaire returns, correspondingly, detected a significant deviation from independence, with $\chi^{2}(1)=84.75$,

2 This may have been possible if questionnaires were delivered to the wrong address, or if respondents had only recently moved into the property. 
$p<.001$. However, since the sample was still reasonably balanced between participants and non-participants in the Green Box scheme, no additional trimming of data was undertaken.

\section{Design and Measures}

The relevant predictors of recycling were assessed using quantitative self-report scales in the questionnaire survey, which also asked for relevant demographic information (gender, age, employment status, etc.). Recycling behaviour was assessed using the manual tally of Green Box set-out for each household in the sample. The questionnaire used headings that reflected the overall gist of scales in non-technical language, for example "What my neighbours would want me to do" for the injunctive norm scale. The selection of scales was based on an extensive review of precedents from existing social-psychological literature, with the intention to ensure that scales, where possible, were both relevant and supported by previous testing.

\section{Neighbourhood identification}

The items to tap identification with the neighbourhood were based on Brown, Condor, Mathews, Wade and Williams (1986) and Ellemers, Kortekaas and Ouwerkerk (1999). The ten items to be rated on a 5-point Likert scale included statements such as "Living in this street is an important aspect of who I am" and "I would rather live elsewhere than in this street” (reverse-scaled). Participants were given an additional response option of "don't know" for each item, which was subsequently scored as missing data. The identification scale was internally reliable with Cronbach's $\alpha=0.92$. 


\section{Attitude towards recycling and perceived control over recycling}

Measures of attitudes towards household waste recycling and perceived control over recycling were adapted from Cheung et al. (1999) and included "Participating in the Green Box scheme regularly is the right thing to do" (attitude; 5 items in total, Cronbach's $\alpha=0.88$ ) and "Participating regularly in Green Box recycling is entirely under my own control" (control; 5 items, Cronbach's $\alpha=0.78$ ). These items used the same Likert-type scale as the neighbourhood identification measure.

\section{Self-identity as a recycler and perceived injunctive and descriptive social norms}

Self-identity as a recycler and the perceived injunctive norm to recycle were measured using items from Terry et al. (1999) and included items such as "To engage in household recycling is an important part of who I am" (self-identity; 4 items, Cronbach's $\alpha=0.74$ ) or "My neighbours in this street would like to see others participate in kerbside recycling" (injunctive social norm; 4 items, Cronbach's $\alpha=0.81$ ). These items, again, used 5-point Likert scales. A single additional item tapped the descriptive social norm for recycling by asking for a rough estimate of the proportion of households in the neighbourhood that participated in Green Box recycling. There were seven response options: none, a few, some, around half, many, most, and all.

\section{Personal norm for recycling}

The personal recycling norm was measured using the aforementioned Likert-type response options with items adapted from Hopper \& Nielsen (1991), for example "I feel bad about putting recyclables into the bin" (5 items in total, Cronbach's $\alpha=0.78$ ). 


\section{Intention to recycle}

Both Cheung et al. (1999) and Terry et al. (1999) were drawn upon for items relating to intentions to recycle (e.g. "I will recycle my household waste wherever possible in the future"; 4 items in total, Cronbach's $\alpha=0.86$ ).

\section{Observed recycling behaviour}

Green Box set-out was a binary measure (set out/not set out) corresponding to the manual tally taken during the recycling collection round. This information could be collated with the survey data by means of a unique participant number assigned to each household address at the time of the mail-out and recorded on the questionnaire.

\section{Results}

\section{Confirmatory Factor Analysis of Norm Scales}

To ascertain that items included to measure the personal recycling norm, the injunctive social norm and the descriptive social norm did indeed tap discrete constructs, a confirmatory factor analysis was conducted using the EQS software package. A simple model was tested, in which the 10 questionnaire items were predicted, with some error, by three latent variables (assumed to be the personal, injunctive and descriptive norm). The model specified that the four items measuring the injunctive social norm were predicted only by the first factor, the single item measuring the descriptive social norm only by the second, and the five items measuring personal norms only by the third. The three factors were allowed to 
covary, but the errors attached to the prediction of measurement items were not. The EQS analysis returned a significant $\chi^{2}(32)=112.61, p<.001$, but fit indices less sensitive to sample size were broadly satisfactory $(\mathrm{CFI}=0.94, \mathrm{SRMR}=0.06, \mathrm{RMSEA}=0.09)$. All path coefficients were significant (see Figure 1). Accordingly, all subsequent analyses proceeded to treat the three norm-related scales as separate variables.

\section{INSERT FIGURE 1 ABOUT HERE}

\section{Descriptive Statistics and Data Preparation}

Table 1 shows descriptive statistics and bivariate correlations for all continuous variables. Note the high means for all measures, especially attitude and intention: The sample as a whole was very positively disposed towards recycling and its hypothesised antecedents. Some negative skewness in these sample distributions could not be remedied by any of the common transformations and was disregarded. There were also reliable and sometimes very substantial bivariate correlations between the variables. Frequency counts showed that 305 respondents (57.9\%) had set out their Green Box at the time of the monitoring exercise, while $222(42.1 \%)$ had not.

\section{INSERT TABLE 1 ABOUT HERE}

Following Ajzen's (1991) recommendation, hierarchical regression was used to analyse the prediction of intention and behaviour. Missing values in the predictor variables were imputed using the E-M method provided by the SPSS software package (see Tabachnick \& Fidell, 2001). The first step of each analysis contained the predictors taken 
from Ajzen's original TPB. Subsequent blocks analysed whether additional predictors accounted for extra variance in the outcome. Interactions between neighbourhood identification and the injunctive and descriptive social norm measures were tested by entering the relevant multiplicative terms in their own block after the linear predictors (see Cohen, 1978; Evans, 1991). To overcome problems of multicollinearity between the linear and interaction terms, scores on the former were mean-centred before multiplication, as suggested by Tabachnick and Fidell (2001: pp. 151ff.).

\section{Prediction of Intention}

Hierarchical linear regression was used to test the prediction of intention to recycle. Attitude towards recycling, perceived control over recycling, and personal recycling norm were entered in the first block, followed by self-identity as a recycler, the injunctive and descriptive social norms, and neighbourhood identification in the second. The final block added the interaction terms between identification and injunctive norm and between identification and descriptive norm.

\section{INSERT TABLE 2 ABOUT HERE}

As shown in Table 2, the model with only attitude, control and personal norm as predictors explained a respectable $61 \%$ of the variance in the intention measure $(R=0.78$, $\left.R^{2}=0.61, F(3,523)=273.95, p<.001\right)$. However, prediction was significantly improved by the second block of variables $\left(R=0.80, R^{2}=0.65, F(4,519)=12.85, p<.001\right)$. In addition to attitude $(\beta=0.34, t=8.99, p<.001)$, control $(\beta=0.20, t=5.54, p<.001)$ and personal norm $(\beta=0.12$, $t=3.09, p<.01)$, significant predictors emerged in self-identity $(\beta=0.21, t=5.44, p<.001)$ and 
the descriptive social norm $(\beta=0.09, t=2.57, p<.05)$. Neighbourhood identification and the injunctive social norm were not significant predictors, and the addition of the aforementioned interaction terms did not further improve the model.

\section{Prediction of Behaviour}

A hierarchical logistic regression analysis was conducted to determine which variables predicted whether individuals would or would not set out their Green Box for recycling. In line with the TPB, intention and perceived control were entered in the first step of the analysis. The second block comprised attitude, self-identity, neighbourhood identification and all three norm-related measures, whilst the third added the interactions between neighbourhood identification and the injunctive social norm and between neighbourhood identification and the descriptive social norm.

\section{INSERT TABLE 3 ABOUT HERE}

As shown in Table 3, the basic TPB model made a significant contribution to the prediction of Green Box set-out $\left(\chi^{2}(2)=55.50, p<.001\right)$. The second block of predictors did, however, improve it further, $\left(\chi^{2}(6)=16.20, p<.05\right)$. Although the predictive power of the model (Nagelkerke's $R^{2}=0.17$ ) and its goodness of fit to the data according to the HosmerLemeshow test $\left(\chi^{2}(8)=15.87, p<.05\right)$ remained relatively poor, there were several variables significantly and positively associated with recycling box set-out, namely intention $(\mathrm{OR}=2.31$, Wald=9.81, $p<.01)$, self-identity $(\mathrm{OR}=1.66$, Wald $=6.08, p<.05)$ and the descriptive norm $(\mathrm{OR}=1.26$, Wald $=6.65, p<.05)$. Perceived control and the remaining 
variables were not significant predictors, nor did the addition of interaction terms significantly improve the model. ${ }^{3}$

\section{Moderation and Mediation in the Norm Measures}

Additional analyses were required to examine the complex hypothesis that the relationship between social norms and intention would be at least partially mediated by the personal norm, and that identification with the neighbourhood would moderate the link between social and personal norms. A recently published article and SPSS macro by Preacher, Rucker and Hayes (2007) proffer a workable method to analyse such moderated mediation hypotheses, using bootstrapping to assess directly the reliability of the conditional indirect effect. Separate analyses were conducted using the injunctive social norm and the descriptive social norm as independent variables, while controlling for other linear predictors.

\section{INSERT TABLE 4 ABOUT HERE}

First, the measure of injunctive norms was entered into the SPSS macro as the independent variable, intention as the outcome, personal norms as the mediator, neighbourhood identification as a moderator of the link between injunctive norm and personal norm, and attitude, control, self-identity and descriptive norm as covariates. The upper portion of Table 4 shows the resulting regression models (with covariates given in italics): one to predict the mediator (personal norm) and one to predict the dependent variable

3 Table 3 shows a significant interaction between neighbourhood identification and the descriptive norm for recycling in the final block of the analysis. Follow-up analyses suggest that the descriptive norm may be more predictive of recycling behaviour among individuals with low neighbourhood identification. Yet this should not be considered a substantial finding since the step of adding the interaction terms did not improve the predictive utility of the model overall. 
(intention). The lower portion shows bootstrap estimates of the mediation effect at three values of the moderator (neighbourhood identification): at the mean level of identification and at one standard deviation above and below. Standard errors and significance tests associated with these estimates are also displayed. It is apparent that, although the covariates are highly significant, personal norms are predicted reliably by the injunctive norm $(b=0.20$, $t=4.48, p<.001)^{4}$ and, importantly, by the interaction between injunctive norm and neighbourhood identification $(b=0.08, t=2.19, p<.05)$. Of course, the model for the dependent variable replicates the one described above (see Table 2), except that the interaction between injunctive norm and neighbourhood identification reaches significance $(b=-0.07, t=-2.22$, $p<.05)$ with the corresponding interaction involving descriptive norms not included. The lower portion of the table shows that bootstrap estimates of the indirect effect increase as neighbourhood identification increases: the mediation appears to reach significance at around the mean level of identification in the present sample.

\section{INSERT TABLE 5 ABOUT HERE}

A similar conditional indirect effect was not in evidence for the descriptive norm. Whilst the interaction term between descriptive norm and neighbourhood identification predicted personal norms while controlling for other variables $(b=0.04, t=2.52, p<.05)$, estimates of the mediation effect remained close to zero regardless of the level of identification with the neighbourhood (see Table 5).

4 Note that the SPSS macro (Preacher et al., 2007) returns unstandardised regression coefficients. Standardisation was not judged to be critical to this hypothesis test and was not attempted. 


\section{Discussion}

The aim of the study reported here was to test an extended TPB in the context of household waste recycling, and thereby to address some issues identified in the theory. Specifically, we expected self-identity to add to the prediction of intention and possibly behaviour. Based on the norm activation model (Schwartz, 1977), it was furthermore hypothesised that personal norms would directly predict intentions to recycle, and in turn be predicted by social norms - with a possible moderating role for neighbourhood identification (see Terry et al., 1999). Among social norms, a distinction was drawn between descriptive and injunctive norms (e.g. Cialdini et al., 1991), which were expected potentially to affect intentions and behaviour differently.

The data supported these expectations. Generally, the TPB was corroborated by the present findings, with intention emerging as a significant predictor of actual behaviour, while attitudes, personal norms and perceived control predicted intention. The non-significant regression coefficient of control in the prediction of behaviour seems unproblematic - whilst such a direct effect is allowed by the TPB, Ajzen (1991: p. 185) makes clear that this relationship will not appear if the behaviour is perceived to be under complete volitional control. For most participants, this would have been the case thanks to the convenience of recycling with the Green Box.

The addition of predictors to the original TPB was shown to strengthen the predictive power of the resulting model. Self-identification as a recycler fostered intentions to recycle in our sample over and above attitudes, personal norms and perceived control, supporting the findings of Terry et al. (1999) and adding to the compelling body of evidence that supports an inclusion of self-identity in the TPB (see Conner \& Armitage, 1998). The descriptive norm, too, significantly predicted intention to recycle after the original TPB variables had been accounted for: Participants who were under the impression that their neighbours recycled 
regularly, subsequently seemed to intend to recycle more often themselves. This is in line with previous research in other behavioural domains, where it has been found that descriptive norms may make a contribution to behavioural intentions (e.g. Fekadu \& Kraft, 2002; Sheeran \& Orbell, 1999). It seems possible that, as surmised in the introduction, the public visibility of recycling behaviour makes it amenable to social influence and imitation of neighbours.

Importantly, both self-identity as a recycler and the descriptive social norm for recycling also contributed directly to behaviour, over and above behavioural intentions. Individuals who strongly adopted the role of recyclers were more likely to set out their recycling box, regardless of professed intentions to recycle. This illustrates the value of social-psychological notions of identity and norms in predicting behaviour (see Terry et al., 1999) by showing that identity can influence behaviour and its antecedents at several stages within the system stipulated by the TPB. A similar point can be made about the direct effect on behaviour of the descriptive norm for recycling, which moreover supports the idea from the norm focus theory that descriptive norms are best understood as impressions of adaptive behaviour in a given setting (Reno et al., 1993: p. 104). Perceptions that kerbside recycling is 'the done thing' in the neighbourhood appeared to have direct implications for behaviour.

Support for the mediation of the link between social norms and intention via personal norms (additionally moderated by neighbourhood identification) was equivocal. No indirect effect of descriptive norms was found, regardless of the level of identification with the neighbourhood. This could be an artefact of measurement (i.e., the single-item measure could simply not have correlated as reliably with personal norms as the measure of injunctive norms), but may also reflect an interesting dissociation in how injunctive and descriptive norms influence behaviour - recall that descriptive norms had significant direct effects on both intentions and behaviour. The injunctive norm measure did display the hypothesised 
moderated mediation effect: The interaction between identification and injunctive norm predicted personal norms, personal norms predicted intention, and the indirect effect became significant at moderate to high levels of identification. There was thus some support for the norm activation model (Schwartz, 1977) and the moderation hypothesis (Terry et al., 1999), suggesting with regard to our aim to incorporate the norm activation model into the TPB that it may be productive in future studies to focus on personal norms as direct predictors of intention, and on injunctive social norms as predictors of those.

Although the present investigation has many strengths, including an observational measure of behaviour and a substantial field sample, it also has certain limitations. The practicalities of the field setting allowed only for a dichotomous measurement of behaviour: whether individuals did or did not set out their recycling boxes. Although logistic regression is an adequate tool to test the prediction of such dichotomous variables, it limits the comparability of the present results with past research on the TPB, where Ajzen (1991: p. 187) reports multiple correlation coefficients of around 0.51 in the prediction of behaviour. Also, it could be argued that the finding of a direct predictive link between the descriptive social norm and behaviour might partly be due to the peculiarities of our single-item assessment of the descriptive norm. Our second study sought to replicate the first while addressing these shortcomings.

\section{STUDY 2}

Whilst our second study did not include an objective measurement of behaviour, selfreports of recycling ensured a more differentiated outcome variable. Moreover, we added a multi-item scale for the descriptive social norm to fit this measure more elegantly into the questionnaire. With these exceptions, the measures were very similar to those in Study 1. For 
this investigation, we used a true random sample extracted from Guildford Borough's electoral register. It was expected that the results of the first study would be largely replicated: We expected support for the TPB; a contribution of self-identity as a recycler and the descriptive norm for recycling to the prediction of intention, behaviour, or both; and an indirect effect between injunctive social norms and intention via personal norms, potentially moderated by neighbourhood identification.

\section{Method}

\section{Design and Materials}

Self-reported recycling participation and relevant predictor variables were measured using a Likert-type questionnaire very similar to the one used in Study 1. Since these questions were part of a more extensive survey, care was taken to minimise the length of the inventory while preserving its integrity. The multi-item scales were shortened by between one and three items where item-total correlations and scale reliability statistics from Study 1 seemed to allow for this. Moreover, the conspicuous headings for each scale were not used in this second questionnaire.

The descriptive social norm for recycling was this time measured using three items: "Most of my own neighbours recycle", "Most of my neighbours like to recycle wherever possible", and "People around here do not make much use of recycling facilities" (the latter item was reverse-scaled). Self-reported recycling behaviour was measured by an item at the end of the questionnaire, where respondents were asked to indicate whether they recycled their household waste at every collection, most of the time, about half of the time, less than 
half of the time, or never at all. Scale reliabilities were broadly satisfactory for all the multiitem scales, including attitude (5 items, Cronbach's $\alpha=0.76$ ), self-identity ( 4 items, $\alpha=0.79$ ), descriptive norm ( 3 items, $\alpha=0.78$ ), injunctive norm ( 3 items, $\alpha=0.78$ ), personal norm (4 items, $\alpha=0.66$ ), perceived control ( 5 items, $\alpha=0.65$ ), neighbourhood identification ( 7 items, $\alpha=0.84$ ), and intention to recycle (4 items, $\alpha=0.83$ ).

\section{Participants and Procedure}

The questionnaire was mailed out to a sample of 2,000 Guildford Borough residents randomly selected from the electoral register. Again, a free-post return envelope was provided and a prize draw for $£ 50$ worth of retail vouchers announced among those residents who returned a completed survey. Completed questionnaires were returned by $270(13.5 \%)$ households. For present analyses, six of these respondents were deleted after reporting that they were not covered by the Green Box service. Among the remaining 264 participants, 80 $(30.3 \%)$ were male, $164(62.1 \%)$ were female, and $20(7.6 \%)$ did not disclose their gender. The representation of age groups was very similar to the pattern obtained in the first study, with the youngest age groups somewhat under-represented: $3.4 \%$ were under 21 years old, $12.1 \%$ were between 21 and 30, and roughly twenty per cent each were in the 31-40 (19.3\%), $41-50(24.6 \%), 51-60(17.8 \%)$ and over-61 (21.6\%) age brackets. 


\section{Results}

\section{Confirmatory Factor Analysis of Norm Scales}

As in Study 1, a confirmatory factor analysis was run using EQS to verify the factor structure of the three norm scales. The model specified was the same in principle as before: Items measuring the injunctive social norm were specified to be predicted by the first factor but not by the other two; items measuring the descriptive social norm were supposed to be predicted only by the second factor; and items measuring personal norms were expected to be predicted exclusively by the third latent variable. Again, covariance was allowed between the factors, but not between error terms. The analysis yielded $\chi^{2}(32)=90.28, p<.001, \mathrm{CFI}=0.90$, SRMR=0.07, RMSEA=0.11. Whilst this model fit would usually be considered marginal, a Lagrange multiplier test for the inclusion of additional paths did not find any significant loadings over and above the initial model specification. Differentiation between the three types of norm was therefore judged to be adequate. Again, all path coefficients were significant (see Figure 2).

\section{INSERT FIGURE 2 ABOUT HERE}

\section{Descriptive Statistics and Data Preparation}

Descriptive statistics and bivariate correlations are shown in Table $6 .^{5}$ There are noteworthy parallels to Study 1 in the overall very positive stance towards recycling and the

5 The self-reported behaviour measure was recoded so that high scores indicated a greater frequency of kerbside recycling. 
antecedent variables. Distributions within the sample were again skewed, but all in the same (negative) direction. Some of the bivariate correlations suggest similar patterns of relationships as observed in the first study, including the strong links between behaviour and intention $(r=0.46, p<.001)$ as well as self-identity $(r=0.37, p<.001)$. Imputation of missing values to preserve power for the multiple regression analyses was imperative because of the relatively large proportion of missing data on the injunctive norm measure. Precautionary comparisons using unpaired $t$ tests revealed no systematic difference on any of the remaining variables between those participants who had provided data on injunctive norms and those who had not. Missing data were therefore replaced with E-M estimates for the regression analyses, as they had been in Study 1. Mean-centring of injunctive norm, descriptive norm and neighbourhood identification scores, and the calculation of interaction terms, were also handled in the same way as in the previous study.

\section{INSERT TABLE 6 ABOUT HERE}

\section{Prediction of Intention}

Hierarchical linear regression was used to analyse the prediction of intentions to recycle, in a manner analogous to Study 1 . Attitude, personal norm and perceived control were entered in the first block, all remaining linear predictors in the second, and the two interactions in the third. As shown in Table 7, the first model explained a sizeable amount of variance in intentions $\left(R=0.72, R^{2}=0.52, F(3,260)=92.23, p<.001\right)$ but was further improved with the second step $\left(R=0.75, R^{2}=0.56, F(4,256)=6.83, p<.001\right)$. Replicating results from Study 1 , the significant predictors were attitude $(\beta=0.31, t=5.83, p<.001)$, personal norm $(\beta=0.17, t=2.96, p<.01)$, control $(\beta=0.20, t=3.86, p<.001)$, self-identity $(\beta=0.23, t=4.18$, 
$p<.001)$ and the descriptive norm $(\beta=0.14, t=2.69, p<.01)$. The addition of the interaction terms did not improve prediction.

\section{INSERT TABLE 7 ABOUT HERE}

\section{Prediction of Behaviour}

The prediction of behaviour was also analysed using hierarchical linear regression. As in Study 1, intention and control - the variables stipulated by the TPB - were entered in the first block of variables, all other linear predictors in the second, and the interactions in the third. Table 8 shows that the analysis including just intention and control as predictors $\left(R=0.46, R^{2}=0.21, F(2,261)=34.22, p<.001\right)$ was improved upon by the second block of variables $\left(R=0.50, R^{2}=0.25, F(6,255)=2.28, p<.05\right)$. Just as in Study 1 , significant coefficients were found for intention $(\beta=0.29, t=3.57, p<.001)$, self-identity $(\beta=0.15, t=1.97$, $p<.05)$ and the descriptive norm $(\beta=0.20, t=2.91, p<.01)$, but not for perceived control ( $\beta=0.03, t=0.49, p=.63)$ or the other predictors. The interaction terms did not make any further contribution to the model.

\section{INSERT TABLE 8 ABOUT HERE}

\section{Moderation and Mediation in the Norm Measures}

Analysis of moderated mediation was conducted in the same way as in Study 1. To test for the indirect effect of injunctive social norms on intention via personal norms, conditional upon neighbourhood identification, these variables were entered accordingly in 
the SPSS macro from Preacher et al. (2007), with all other linear predictors added as covariates. Table 9 shows that the interaction between neighbourhood identification and injunctive norm was indeed predictive of personal norms $(b=0.20, t=2.95, p<.01)$, which in turn significantly predicted intention $(b=0.16, t=3.17, p<.01$; see also Table 7$)$. However, bootstrap estimates in the lower part of the table demonstrate that the indirect effect of injunctive norms via personal norms was not significant within one standard deviation on either side of the sample mean on the neighbourhood identification measure. In fact, additional analyses in which the indirect effect was calculated at the observed minimum and maximum of the moderator revealed that it did not reach significance at either extreme $\left(z_{\text {low }}=\right.$ -1.786, $\left.p=.07, z_{\text {high }}=1.808, p=.07\right)$.

\section{INSERT TABLE 9 ABOUT HERE}

Table 10 summarises the corresponding analysis involving descriptive social norms as the independent variable. Again, the interaction between descriptive norm and identification significantly predicted personal norms when controlling for other linear predictors $(b=0.13$, $t=2.21, p<.05$ ), but an indirect effect of descriptive norms via personal norms was not in evidence.

\section{INSERT TABLE 10 ABOUT HERE}

\section{Discussion}

Our second study, which used a multi-item measure of the descriptive norm and a five-point scale of self-reported recycling behaviour, succeeded in replicating the main results 
of the first. The data were generally supportive of the TPB, whilst also making a case for the addition of more social-psychological elements to the model. Most importantly, Study 2 supported the direct linear effects of a descriptive norm for recycling and a recycler selfidentity upon behaviour, in addition to the already substantial contribution of intention. The amount of variance in self-reported behaviour explained by these predictors was comparable to similar studies (Ajzen, 1991). Also in line with Study 1, intentions to recycle were predicted by self-identity and the descriptive norm in addition to attitude, personal norm and perceived control. With regard to the moderated mediation hypothesis, it was clear that the interaction between neighbourhood identification and social norms (both injunctive and descriptive) added to the prediction of personal norms as expected. However, indirect effects on intention via personal norms were too weak to attain significance. In the case of the descriptive norm, it seems possible that this is due to its substantial direct effect on intention (see Study 1). As for the injunctive norm, estimates suggest that the indirect effect is negative when identification is low and positive when it is high, but the test of mediation did not reach statistical significance within the range of observed identification scores. This analysis remains inconclusive.

It should be noted that, although the results of this study corroborate those from Study 1, there remain limitations. First, both studies were conducted within the area of Guildford Borough Council's Green Box collection scheme and therefore do not necessarily tell us much about other geographical areas or facilities for household waste recycling. Second, participation in these surveys was voluntary, and there is no guarantee that responses were representative. We can tell that our sample was varied, but - for example, with regard to the age distribution or participation rates - not perfectly reflective of the population. Third, our results are quantitative and correlational, and can therefore not be drawn upon for firm 
conclusions regarding causal relationships or the specific meanings attached by individuals to the psychological constructs we attempted to measure.

\section{CONCLUSIONS}

The present research, heeding Ajzen's (1991) challenge to identify additional predictors that improve the prediction of intentions or behaviour over and above the original variables of the TPB, has provided some indication that social-psychological concepts of norms and identity may be capable of expanding and refining its normative and social aspects. The two studies reported here offered substantial corroboration for the TPB in a household recycling setting by providing support for the relationships it specifies between behaviour and its antecedents; given the relative scarcity of research that measures behaviour at all (see Armitage \& Conner, 2001), this aspect is in itself worth a mention.

Drawing upon the norm activation model (Schwartz, 1977), we tried to contribute to an alternative operationalisation of the subjective norm by hypothesising that personal norms would significantly predict intentions, and in turn be predicted by social norms. In line with some of the research on social identity and the TPB (Terry et al., 1999), we also surmised that the extent to which social norms are adopted as personal would depend on the degree of identification with the group from which the norm originates. These expectations were not fully met. Whilst the interaction between neighbourhood identification and social norm measures did predict personal norms, and personal norms predicted intentions in all analyses, there was only very limited evidence of a significant mediation effect as suggested by the norm activation model. The most likely explanation for this is a statistical one: With several other, highly influential predictors included in the analysis, some multicollinearity was inevitable. Indeed, additional analyses, in which only the social norm, personal norm and 
intention measures were included, found the predicted mediation. These analyses are not reported here because our work was not primarily a test of the norm activation model, nor should the lack of significant mediation with all covariates included be seen as a challenge to it.

The distinction between injunctive and descriptive social norms (Cialdini et al., 1991) yielded some interesting effects, which were largely replicated across our two studies. The descriptive norm - the perception that neighbours were setting out their recycling box for collection - made significant direct contributions to both intentions and behaviour. Referring back to norm focus theory, it may seem plausible that this descriptive norm was focal and therefore more potent at the time: The visibility of recycling with the Green Box is apt to function as a reminder of normative behaviour in the neighbourhood. ${ }^{6}$ Yet the injunctive norm - the sense that neighbours would expect others to recycle - was still influential to personal norms, which in turn predicted intentions. Whilst the norm focus theory could thus be beneficial to the TPB approach by explaining such situational variation in the impact of social norms, the TPB seems to be able to demonstrate a way in which norms may have less direct effects on behaviour. At the least, a dissociation between injunctive and descriptive social norms was well supported in the present research and may be useful in future investigations.

Finally, our two studies unequivocally strengthen the case for an inclusion of selfidentity in the prediction of intentions and behaviour. The data show that self-identity is not only influential to intentions, but makes an additional contribution to behaviour itself (see Bissonnette \& Contento, 2001; Theodorakis, 1994). Future analyses could examine more

6 An alternative interpretation, kindly pointed out by an anonymous reviewer, would be that regular recyclers are more likely to notice the Green Boxes set out for collection by neighbours. To some extent, this caveat extends to all correlational analyses - no firm conclusions can be drawn about causality or directionality. Our preference for the explanation that norms are prior to behaviours stems from the experimental work on norm focus theory (e.g. Cialdini et al., 1990) and the general assumptions of the TPB (Ajzen, 1991). 
closely the interplay between self-identity and other variables within the TPB. An association between social norms and self-identity was found in further analyses of the data set presented here (Nigbur, Lyons, \& Uzzell, 2005); moderation and mediation involving self-identity were also outside the remit of the present paper, but some possible relationships have been outlined in the literature (e.g. Conner \& McMillan, 1999).

In addition to these theoretical concerns, our investigation has some intriguing practical implications. The direct bearing of descriptive norms on behaviour, observed in both of our studies, could provide a theoretical explanation for lay observations of the osmotic effects of neighbourhood behaviour - the sense that 'in Rome, one does as the Romans do'. This is encouraging for policy interventions, such as those on recycling, that try to change behaviour rather than just creating awareness: It implies that others will follow if some people can be persuaded.

Self-identity as a recycler, too, had significant effects on both intentions and behaviour, and interventions to promote certain behaviours therefore should not ignore this variable. In order to foster recycling, for example, the present findings suggest that it might be a workable strategy to employ interventions that make people feel like recyclers - for example, by giving them positive feedback on recycling participation rates in their area. This is in line with findings from educational settings (Miller, Brickman, \& Bolen, 1975), where pupils' tidiness and mathematical abilities benefited more from messages that characterised them as tidy people or good at maths than from those that exhorted them to be tidier or try harder.

Finally, the finding that the injunctive social norm for recycling informed personal norms corroborates the suggestion from norm focus theorists that interventions to emphasise injunctive norms have great potential for changing behaviour (Reno et al., 1993). The awareness that certain types of behaviour are sanctioned by a relevant social group is 
assumed to lead to norm-congruent behaviour both by the norm focus theory and the social identity approach. Evidence from norm-focus experiments (Cialdini et al., 1991; Cialdini et al., 1990; Kallgren et al., 2000; Reno et al., 1993) demonstrates this effect of norms; the present inquiry shows, in line with the TPB and social identity concepts, the mechanism through which it occurs. Identifiers accept the injunctive group norm as a personal norm and act upon it. Interventions to create injunctive social norms for recycling or to make them more focal therefore have the capacity to breed 'recyclers by conviction', whilst a changing descriptive norm creates 'recyclers by imitation'. The convergence over time between injunctive and descriptive norms in cohesive groups, including closely knit neighbourhoods, is an encouraging mechanism through which behavioural change may become selfmaintaining and permanent. 


\section{References}

Ajzen, I. (1988). Attitudes, personality and behaviour. Milton Keynes: Open University Press.

Ajzen, I. (1991). The theory of planned behaviour. Organisational Behaviour and Human Decision Processes, 50(2), 179-211.

Ajzen, I., \& Fishbein, M. (1977). Attitude-behaviour relations: A theoretical analysis and review of empirical research. Psychological Bulletin, 84, 888-918.

Armitage, C. J., \& Conner, M. (2001). Efficacy of the theory of planned behaviour: A metaanalytic review. British Journal of Social Psychology, 40(4), 471-499.

Astrom, A. N., \& Rise, J. (2001). Young adults' intention to eat healthy food: Extending the theory of planned behaviour. Psychology and Health, 16(2), 223-237.

Bissonnette, M. M., \& Contento, I. R. (2001). Adolescents' perspectives and food choice behaviours in terms of the environmental impacts of food production practices: Application of a psychosocial model. Journal of Nutrition Education, 33(2), 72-82.

Boldero, J. (1995). The prediction of household recycling of newspapers: The role of attitudes, intentions, and situational factors. Journal of Applied Social Psychology, $25(5), 440-462$.

Bratt, C. (1999). The impact of norms and assumed consequences on recycling behaviour. Environment and Behaviour, 31(5), 630-656.

Brown, R., Condor, S., Mathews, A., Wade, G., \& Williams, J. A. (1986). Explaining 
intergroup differentiation in an industrial organisation. Journal of Occupational Psychology, 59, 273-286.

Cheung, S. F., Chan, D. K. S., \& Wong, Z. S. Y. (1999). Re-examining the theory of planned behaviour in understanding waste-paper recycling. Environment and Behaviour, 31(5), 587-612.

Cialdini, R. B., Kallgren, C. A., \& Reno, R. R. (1991). A focus theory of normative conduct: A theoretical refinement and re-evaluation of the role of norms in human behaviour. In M. P. Zanna (Ed.), Advances in experimental social psychology, Vol. 24 (pp. 20134). London: Academic Press.

Cialdini, R. B., Reno, R. R., \& Kallgren, C. A. (1990). A focus theory of normative conduct: Recycling the concept of norms to reduce littering in public places. Journal of Personality and Social Psychology, 58(6), 1015-1026.

Cohen, J. (1978). Partialled products are interactions; partialled powers are curve components. Psychological Bulletin, 85(4), 858-866.

Conner, M., \& Armitage, C. J. (1998). Extending the theory of planned behaviour: A review and avenues for further research. Journal of Applied Social Psychology, 28(15), 14291464.

Conner, M., \& McMillan, B. (1999). Interaction effects in the theory of planned behaviour: Studying cannabis use. British Journal of Social Psychology, 38(2), 195-222.

Ellemers, N., Kortekaas, P., \& Ouwerkerk, J. W. (1999). Self-categorisation, commitment to the group and social self-esteem as related but distinct aspects of social identity. European Journal of Social Psychology, 29, 371-389. 
Evans, M. G. (1991). The problem of analysing multiplicative composites: Interactions revisited. American Psychologist, 46(1), 6-15.

Fekadu, Z., \& Kraft, P. (2001). Self-identity in planned behaviour perspective: Past behaviour and its moderating effects on self-identity-intention relations. Social Behaviour and Personality, 29(7), 671-685.

Fekadu, Z., \& Kraft, P. (2002). Expanding the theory of planned behaviour: The role of social norms and group identification. Journal of Health Psychology, 7(1), 33-43.

Fishbein, M., \& Ajzen, I. (1975). Belief, attitude, intention and behaviour: An introduction to theory and research. Reading, MA: Addison-Wesley.

Hopper, J. R., \& Nielsen, J. M. (1991). Recycling as altruistic behaviour: Normative and behavioural strategies to expand participation in a community recycling programme. Environment and Behaviour, 23(2), 195-220.

Kaiser, F. G., Hübner, G., \& Bogner, F. X. (2005). Contrasting the theory of planned behaviour with the value-belief-norm model in explaining conservation behaviour. Journal of Applied Social Psychology, 35(10), 2150-2170.

Kallgren, C. A., Reno, R. R., \& Cialdini, R. B. (2000). A focus theory of normative conduct: When norms do and do not affect behaviour. Personality and Social Psychology Bulletin, 26(8), 1002-1012.

Mannetti, L., Pierro, A., \& Livi, S. (2004). Recycling: Planned and self-expressive behaviour. Journal of Environmental Psychology, 24(2), 227-236.

Miller, R. L., Brickman, P., \& Bolen, D. (1975). Attribution versus persuasion as a means for modifying behaviour. Journal of Personality and Social Psychology, 31(3), 430-441. 
Minton, A. P. (1995). Chronic norm focus: The interaction effects of norms and dispositions on environmentally friendly consumer behaviours. Dissertation Abstracts International, Section A (Humanities and Social Sciences), 55(12-A), 3922.

Nigbur, D., Lyons, E., \& Uzzell, D. (2005, July). It's not what you do, it's why you do it: Using an extended theory of planned behaviour to predict kerbside recycling. Paper presented at the 14th General Meeting of the European Association for Experimental Social Psychology, Würzburg.

Preacher, K. J., Rucker, D. D., \& Hayes, A. F. (2007). Addressing moderated mediation hypotheses: Theory, methods, and prescriptions. Multivariate Behavioural Research, $42(1), 185-227$.

Reno, R. R., Cialdini, R. B., \& Kallgren, C. A. (1993). The trans-situational influence of social norms. Journal of Personality and Social Psychology, 64(1), 104-112.

Schwartz, S. H. (1977). Normative influences on altruism. In L. Berkowitz (Ed.), Advances in experimental social psychology, Vol. 10 (pp. 221-79). London: Academic Press.

Schwartz, S. H., \& Howard, J. A. (1980). Explanations of the moderating effect of responsibility denial on the personal norm-behaviour relationship. Social Psychology Quarterly, 43(4), 441-446.

Sheeran, P., \& Orbell, S. (1999). Augmenting the theory of planned behaviour: Roles for anticipated regret and descriptive norms. Journal of Applied Social Psychology, 29(10), 2107-2142.

Sparks, P. (2000). Subjective expected utility-based attitude-behaviour models: The utility of self-identity. In D. J. Terry \& M. A. Hogg (Eds.), Attitudes, behaviour, and social 
context: The role of norms and group membership. Applied social research (pp. 3146). Hillsdale: Lawrence Erlbaum Associates.

Sparks, P., \& Guthrie, C. A. (1998). Self-identity and the theory of planned behaviour: A useful addition or an unhelpful artifice? Journal of Applied Social Psychology, 28(15), 1393-1410.

Steadman, L., Rutter, D. R., \& Field, S. (2002). Individually elicited versus modal normative beliefs in predicting attendance at breast screening: Examining the role of belief salience in the Theory of Planned Behaviour. British Journal of Health Psychology, 7(3), 317-330.

Steinheider, B., Fay, D., Hilburger, T., Hust, I., Prinz, L., Vogelgesang, F., et al. (1999). Soziale Normen als Prädiktoren von umweltbezogenem Verhalten. Zeitschrift für Sozialpsychologie, 30(1), 40-56.

Stern, P. C., \& Dietz, T. (1994). The value basis of environmental concern. Journal of Social Issues, 50(3), 65-84.

Stern, P. C., Dietz, T., Abel, T., Guagnano, G. A., \& Kalof, L. (1999). A value-belief-norm theory of support for social movements: The case of environmentalism. Human Ecology Review, 6, 81-97.

Stryker, S. (1987). Identity theory: Developments and extensions. In K. Yardley \& T. Honess (Eds.), Self and identity: Psychosocial perspectives (pp. 89-103). New York: John Wiley \& Sons.

Stryker, S., \& Burke, P. J. (2000). The past, present, and future of an identity theory. Social Psychology Quarterly, 63(4), 284-297. 
Tabachnick, B. G., \& Fidell, L. S. (2001). Using multivariate statistics (4th ed.). London: Allyn \& Bacon.

Tajfel, H., \& Turner, J. C. (1986). The social identity theory of intergroup behaviour. In S. Worchel \& W. G. Austin (Eds.), Psychology of intergroup relations (pp. 7-24). Chicago: Nelson-Hall.

Terry, D. J., Hogg, M. A., \& White, K. M. (1999). The theory of planned behaviour: Selfidentity, social identity and group norms. British Journal of Social Psychology, 38(3), $225-244$

Theodorakis, Y. (1994). Planned behaviour, attitude strength, role identity, and the prediction of exercise behaviour. Sport Psychologist, 8(2), 149-165.

Turner, J. C. (1999). Some current issues in research on social identity and self-categorisation theories. In N. Ellemers, R. Spears \& B. Doosje (Eds.), Social identity: Context, commitment, content (pp. 6-34). Oxford: Blackwell.

Turner, J. C., Hogg, M. A., Oakes, P. J., Reicher, S. D., \& Wetherell, M. S. (Eds.) (1987). Rediscovering the social group: A self-categorisation theory. Oxford: Blackwell. 


\begin{tabular}{|c|c|c|c|c|c|c|c|c|c|c|c|}
\hline & & $N$ & $M$ & $S D$ & 1 & 2 & 3 & 4 & 5 & 6 & 7 \\
\hline 1. & $\begin{array}{l}\text { neighbourhood } \\
\text { identification }\end{array}$ & 525 & 3.65 & 0.82 & 1 & & & & & & \\
\hline 2. & $\begin{array}{l}\text { attitude towards } \\
\text { recycling }\end{array}$ & 517 & 4.47 & 0.60 & $.23^{*}$ & 1 & & & & & \\
\hline 3. & $\begin{array}{l}\text { self-identity as a } \\
\text { recycler }\end{array}$ & 525 & 3.91 & 0.74 & $.26^{*}$ & $.64^{*}$ & 1 & & & & \\
\hline 4. & $\begin{array}{l}\text { descriptive social } \\
\text { norm for recycling }\end{array}$ & 521 & 4.88 & 1.39 & $.40^{*}$ & $.31^{*}$ & $.26^{*}$ & 1 & & & \\
\hline 5. & $\begin{array}{l}\text { injunctive social norm } \\
\text { for recycling }\end{array}$ & 485 & 3.65 & 0.64 & $.47^{\star}$ & $.26^{*}$ & $.34^{\star}$ & $.62^{*}$ & 1 & & \\
\hline 6. & $\begin{array}{l}\text { personal norm for } \\
\text { recycling }\end{array}$ & 509 & 3.84 & 0.70 & $.26^{*}$ & $.58^{*}$ & $.69^{*}$ & $.30^{*}$ & $.43^{*}$ & 1 & \\
\hline 7. & perceived control & 508 & 4.19 & 0.53 & $.22^{*}$ & $.65^{*}$ & $.61^{*}$ & $.24^{*}$ & $.35^{*}$ & $.60^{*}$ & 1 \\
\hline 8. & intention to recycle & 518 & 4.28 & 0.66 & $.28^{*}$ & $.72^{*}$ & $.68^{*}$ & $.36^{*}$ & $.38^{*}$ & $.63^{*}$ & $.67^{\star}$ \\
\hline
\end{tabular}

Table 1: Descriptive statistics and bivariate correlations for Study 1. Asterisked correlations are significant at the $5 \%$ level. 


\begin{tabular}{|c|c|c|c|c|c|c|c|}
\hline Block & Predictors & $\boldsymbol{R}$ & $R^{2}$ & $\boldsymbol{F}$ & df & $\beta$ & $t$ \\
\hline \multirow[t]{3}{*}{1} & attitude & .782 & .611 & $273.953^{* * *}$ & 3,523 & .421 & $11.437^{\star \star \star}$ \\
\hline & control & & & & & .245 & $6.506^{\star * *}$ \\
\hline & personal norm & & & & & .241 & $6.752^{\star \star \star}$ \\
\hline \multirow[t]{7}{*}{2} & attitude & .804 & 646 & $12.852^{\star \star \star}$ & 4,519 & .341 & $8.991^{* * *}$ \\
\hline & control & & & & & .204 & $5.539^{\star \star \star}$ \\
\hline & personal norm & & & & & .120 & $3.091^{* *}$ \\
\hline & self-identity & & & & & .214 & $5.444^{\star * *}$ \\
\hline & neighbourhood identification & & & & & .026 & .879 \\
\hline & injunctive social norm & & & & & .037 & 1.052 \\
\hline & descriptive social norm & & & & & .086 & $2.571^{*}$ \\
\hline \multirow[t]{9}{*}{3} & attitude & .806 & .650 & 2.512 & 2,517 & .339 & $8.946^{\star * *}$ \\
\hline & control & & & & & .200 & $5.425^{\star * \star}$ \\
\hline & personal norm & & & & & .129 & $3.313^{\star *}$ \\
\hline & self-identity & & & & & .215 & $5.489^{* * *}$ \\
\hline & neighbourhood identification & & & & & .015 & .505 \\
\hline & injunctive social norm & & & & & .025 & .703 \\
\hline & descriptive social norm & & & & & .080 & $2.370^{\star}$ \\
\hline & identification $\times$ injunctive norm & & & & & -.054 & -1.553 \\
\hline & identification $\times$ descriptive norm & & & & & -.012 & -.345 \\
\hline
\end{tabular}

Table 2: Prediction of intentions to recycle, Study 1. *** $p<.001, * * p<.01, * p<.05$ 


\begin{tabular}{|c|c|c|c|c|c|c|}
\hline Block & Predictors & Nagelkerke's $R^{2}$ & $\chi^{2}$ & df & OR (exp b) & Wald \\
\hline 1 & $\begin{array}{l}\text { intention } \\
\text { control }\end{array}$ & .134 & $55.501^{* * *}$ & 2 & $\begin{array}{c}3.464 \\
.824\end{array}$ & $\begin{array}{c}30.592^{\star \star \star} \\
.604\end{array}$ \\
\hline \multirow[t]{8}{*}{2} & intention & .171 & $16.201^{*}$ & 6 & 2.314 & $9.811^{* *}$ \\
\hline & control & & & & .702 & 1.625 \\
\hline & attitude & & & & 1.201 & .517 \\
\hline & personal norm & & & & .877 & .387 \\
\hline & self-identity & & & & 1.659 & $6.077^{*}$ \\
\hline & neighbourhood identification & & & & 1.082 & .354 \\
\hline & injunctive social norm & & & & .787 & 1.291 \\
\hline & descriptive social norm & & & & 1.255 & $6.654^{*}$ \\
\hline \multirow[t]{10}{*}{3} & intention & 182 & 4.880 & 2 & 2.324 & $9.801^{\star *}$ \\
\hline & control & & & & 692 & 1.724 \\
\hline & attitude & & & & 1.187 & .449 \\
\hline & personal norm & & & & .880 & .364 \\
\hline & self-identity & & & & 1.642 & $5.726^{*}$ \\
\hline & neighbourhood identification & & & & 1.081 & .321 \\
\hline & injunctive social norm & & & & .810 & .934 \\
\hline & descriptive social norm & & & & 1.244 & $5.885^{*}$ \\
\hline & identification $\times$ injunctive norm & & & & 1.561 & 3.514 \\
\hline & identification $\times$ descriptive norm & & & & .803 & $3.878^{*}$ \\
\hline
\end{tabular}

Table 3: Prediction of recycling behaviour, Study 1. *** $p<.001, * * p<.01, * p<.05$ 


\begin{tabular}{|c|c|c|c|c|}
\hline & outcome & predictor & $\boldsymbol{b}$ & $t$ \\
\hline \multirow[t]{7}{*}{ mediator model } & personal norm & injunctive social norm & .195 & $4.484^{\star \star \star}$ \\
\hline & & neighbourhood identification & .005 & .188 \\
\hline & & identification $\times$ injunctive norm & .079 & $2.187^{*}$ \\
\hline & & self-identity & .378 & $10.055^{\star * *}$ \\
\hline & & control & .284 & $5.315^{\star * *}$ \\
\hline & & attitude & .165 & $3.385^{\star \star *}$ \\
\hline & & descriptive social norm & .004 & .216 \\
\hline \multirow[t]{8}{*}{ DV model } & intention & personal norm & .122 & $3.301^{* * *}$ \\
\hline & & injunctive social norm & .026 & .688 \\
\hline & & neighbourhood identification & .013 & .554 \\
\hline & & identification $\times$ injunctive norm & -.068 & $-2.217^{\star}$ \\
\hline & & self-identity & .191 & $5.514^{\star * *}$ \\
\hline & & control & .253 & $5.463^{* \star *}$ \\
\hline & & attitude & .374 & $8.963^{\star \star \star}$ \\
\hline & & descriptive social norm & .038 & $2.421^{*}$ \\
\hline
\end{tabular}

bootstrap estimates at specific values of the moderator (5000 bootstrap samples)

\begin{tabular}{lccc}
\hline \multicolumn{1}{c}{ identification } & indirect effect estimate & SE & $\boldsymbol{Z}$ \\
\hline 1 SD below mean & .016 & .009 & 1.676 \\
mean & .024 & .012 & $2.019^{*}$ \\
1 SD above mean & .032 & .016 & $2.016^{*}$ \\
\hline
\end{tabular}

Table 4: Moderated mediation involving injunctive norms, personal norms and neighbourhood identification, Study 1 .

$* p<.05, * * p<.01, * * * p<.001$. 


\begin{tabular}{|c|c|c|c|c|}
\hline & outcome & predictor & $\boldsymbol{b}$ & $t$ \\
\hline \multirow[t]{7}{*}{ mediator model } & personal norm & descriptive social norm & .007 & .376 \\
\hline & & neighbourhood identification & .010 & .344 \\
\hline & & identification $\times$ descriptive norm & 041 & $2.518^{\star}$ \\
\hline & & self-identity & .381 & $10.171^{* * *}$ \\
\hline & & control & .288 & $5.404^{* * *}$ \\
\hline & & attitude & .166 & $3.407^{* * *}$ \\
\hline & & injunctive social norm & .186 & $4.318^{* * *}$ \\
\hline \multirow[t]{8}{*}{ DV model } & intention & personal norm & .121 & $3.255^{\star *}$ \\
\hline & & descriptive social norm & .037 & $2.354^{*}$ \\
\hline & & neighbourhood identification & .014 & .562 \\
\hline & & identification $\times$ descriptive norm & -.022 & -1.614 \\
\hline & & self-identity & .188 & $5.518^{* * *}$ \\
\hline & & control & .251 & $5.409^{\star * *}$ \\
\hline & & attitude & .374 & $8.946^{* * *}$ \\
\hline & & injunctive social norm & .036 & .954 \\
\hline
\end{tabular}

bootstrap estimates at specific values of the moderator ( 5000 bootstrap samples)

\begin{tabular}{lccc}
\hline \multicolumn{1}{c}{ identification } & indirect effect estimate & SE & $\boldsymbol{z}$ \\
\hline 1 SD below mean & -.003 & .003 & -1.122 \\
mean & .001 & .003 & .327 \\
1SD above mean & .005 & .004 & 1.173 \\
\hline
\end{tabular}

Table 5: Moderated mediation involving descriptive norms, personal norms and neighbourhood identification, Study 1.

$* p<.05, * * p<.01, * * * p<.001$. 


\begin{tabular}{|c|c|c|c|c|c|c|c|c|c|c|c|c|}
\hline & & $N$ & $M$ & $S D$ & 1 & 2 & 3 & 4 & 5 & 6 & 7 & 8 \\
\hline 1. & $\begin{array}{l}\text { neighbourhood } \\
\text { identification }\end{array}$ & 259 & 3.92 & 0.62 & 1 & & & & & & & \\
\hline 2. & $\begin{array}{l}\text { attitude towards } \\
\text { recycling }\end{array}$ & 261 & 4.58 & 0.45 & 0.12 & 1 & & & & & & \\
\hline 3. & $\begin{array}{l}\text { self-identity as a } \\
\text { recycler }\end{array}$ & 260 & 3.78 & 0.72 & 0.08 & $0.47^{*}$ & 1 & & & & & \\
\hline 4. & $\begin{array}{l}\text { descriptive norm for } \\
\text { recycling }\end{array}$ & 236 & 3.85 & 0.70 & $0.35^{*}$ & $0.17^{*}$ & $0.16^{*}$ & 1 & & & & \\
\hline 5. & $\begin{array}{l}\text { injunctive norm for } \\
\text { recycling }\end{array}$ & 209 & 3.67 & 0.68 & $0.23^{*}$ & $0.23^{*}$ & $0.28^{*}$ & $0.63^{*}$ & 1 & & & \\
\hline 6. & $\begin{array}{l}\text { personal norm for } \\
\text { recycling }\end{array}$ & 261 & 4.09 & 0.59 & $0.18^{*}$ & $0.55^{\star}$ & $0.59^{*}$ & $0.19^{*}$ & $0.24^{*}$ & 1 & & \\
\hline 7. & perceived control & 257 & 4.10 & 0.50 & $0.16^{*}$ & $0.50^{*}$ & $0.50^{*}$ & $0.15^{\star}$ & $0.21^{*}$ & $0.40^{*}$ & 1 & \\
\hline 8. & intention to recycle & 260 & 4.43 & 0.53 & $0.19^{*}$ & $0.63^{*}$ & $0.59^{*}$ & $0.28^{*}$ & $0.25^{*}$ & $0.57^{*}$ & $0.56^{*}$ & 1 \\
\hline 9. & $\begin{array}{l}\text { self-reported } \\
\text { recycling }\end{array}$ & 260 & 4.57 & 0.79 & 0.11 & $0.31^{*}$ & $0.37^{*}$ & $0.29^{*}$ & $0.16^{*}$ & $0.33^{*}$ & $0.31^{*}$ & $0.46^{*}$ \\
\hline
\end{tabular}

Table 6: Descriptive statistics and bivariate correlations for Study 2. Asterisked correlations are significant at the $5 \%$ level. 


\begin{tabular}{|c|c|c|c|c|c|c|c|}
\hline Block & Predictors & $\boldsymbol{R}$ & $R^{2}$ & $\boldsymbol{F}$ & df & $\beta$ & $t$ \\
\hline \multirow[t]{3}{*}{1} & attitude & .718 & .516 & $92.231^{\star \star *}$ & 3,260 & .338 & $6.127^{\star \star \star}$ \\
\hline & control & & & & & 271 & $5.367^{\star \star \star}$ \\
\hline & personal norm & & & & & 277 & $5.294^{\star \star \star}$ \\
\hline \multirow[t]{7}{*}{2} & attitude & .750 & .562 & $6.830^{\star \star *}$ & 4,256 & 310 & $5.827^{\star * \star}$ \\
\hline & control & & & & & .197 & $3.858^{* * *}$ \\
\hline & personal norm & & & & & 165 & $2.964^{* *}$ \\
\hline & self-identity & & & & & 232 & $4.175^{\star \star \star}$ \\
\hline & neighbourhood identification & & & & & .039 & .875 \\
\hline & injunctive social norm & & & & & -.054 & -1.053 \\
\hline & descriptive social norm & & & & & .141 & $2.691^{* *}$ \\
\hline \multirow[t]{9}{*}{3} & attitude & .752 & .566 & .951 & 2,254 & .301 & $5.556^{\star \star *}$ \\
\hline & control & & & & & .196 & $3.834^{\star * *}$ \\
\hline & personal norm & & & & & 179 & $3.155^{\star *}$ \\
\hline & self-identity & & & & & .229 & $4.118^{\star \star \star}$ \\
\hline & neighbourhood identification & & & & & .037 & .839 \\
\hline & injunctive social norm & & & & & -.047 & -.882 \\
\hline & descriptive social norm & & & & & .128 & $2.384^{*}$ \\
\hline & identification $\times$ injunctive norm & & & & & -.067 & -1.177 \\
\hline & identification $\times$ descriptive norm & & & & & .014 & .237 \\
\hline
\end{tabular}

Table 7: Prediction of intentions to recycle, Study 2. *** $p<.001, * * p<.01, * p<.05$ 


\begin{tabular}{|c|c|c|c|c|c|c|c|}
\hline Block & Predictors & $\boldsymbol{R}$ & $R^{2}$ & $\boldsymbol{F}$ & df & $\beta$ & $t$ \\
\hline 1 & $\begin{array}{l}\text { intention } \\
\text { control }\end{array}$ & .456 & 208 & $34.219^{\star \star \star}$ & 2,261 & $\begin{array}{l}.416 \\
.067\end{array}$ & $\begin{array}{c}6.312^{\star * \star} \\
1.017\end{array}$ \\
\hline \multirow[t]{8}{*}{2} & intention & .498 & 248 & $2.275^{\star}$ & 6,255 & .293 & $3.572^{\star \star *}$ \\
\hline & control & & & & & .034 & .489 \\
\hline & attitude & & & & & .004 & .053 \\
\hline & personal norm & & & & & .043 & .578 \\
\hline & self-identity & & & & & .149 & $1.972^{*}$ \\
\hline & neighbourhood identification & & & & & -.021 & -.351 \\
\hline & injunctive social norm & & & & & -.100 & -1.465 \\
\hline & descriptive social norm & & & & & .203 & $2.907^{\star \star}$ \\
\hline \multirow[t]{10}{*}{3} & intention & .506 & 256 & 1.322 & 2,253 & .298 & $3.628^{\star \star *}$ \\
\hline & control & & & & & .034 & .488 \\
\hline & attitude & & & & & -.005 & -.073 \\
\hline & personal norm & & & & & .027 & .353 \\
\hline & self-identity & & & & & 145 & 1.926 \\
\hline & neighbourhood identification & & & & & -.016 & -.281 \\
\hline & injunctive social norm & & & & & -.087 & -1.250 \\
\hline & descriptive social norm & & & & & .217 & $3.059^{\star \star}$ \\
\hline & identification $\times$ injunctive norm & & & & & -.008 & -.109 \\
\hline & identification $\times$ descriptive norm & & & & & .098 & 1.291 \\
\hline
\end{tabular}

Table 8: Prediction of recycling behaviour, Study 2. *** $p<.001, * * p<.01, * p<.05$ 


\begin{tabular}{lllcc} 
& \multicolumn{1}{c}{ outcome } & \multicolumn{1}{c}{ predictor } & $\boldsymbol{b}$ & $\boldsymbol{t}$ \\
\hline mediator model & personal norm & injunctive social norm & -.007 & -.135 \\
& & neighbourhood identification & .088 & 1.885 \\
& & identification $\times$ injunctive norm & .198 & $2.952^{* *}$ \\
& self-identity & .333 & $7.266^{* * *}$ \\
& & control & .013 & .198 \\
& & attitude & .436 & $6.066^{* * *}$ \\
& & descriptive social norm & .050 & .967 \\
& intention & personal norm & .162 & $3.167^{* *}$ \\
& & injunctive social norm & -.043 & -.949 \\
& neighbourhood identification & .032 & .833 \\
& identification $\times$ injunctive norm & -.076 & -1.361 \\
& & self-identity & .171 & $4.141^{* * *}$ \\
& & control & .209 & $3.842^{* * *}$ \\
& & attitude & .357 & $5.676^{* * *}$ \\
& descriptive social norm & .102 & $2.385^{*}$ \\
\hline
\end{tabular}

\section{bootstrap estimates at specific values of the moderator (5000 bootstrap samples)}

\begin{tabular}{lccc}
\hline \multicolumn{1}{c}{ identification } & indirect effect estimate & SE & $\boldsymbol{Z}$ \\
\hline 1SD below mean & -.019 & .015 & -1.280 \\
mean & -.001 & .010 & -.026 \\
1SD above mean & .019 & .013 & 1.478 \\
\hline
\end{tabular}

Table 9: Moderated mediation involving injunctive norms, personal norms and neighbourhood identification, Study 2.

$* p<.05, * * p<.01, * * * p<.001$. 


\begin{tabular}{lllcc} 
& \multicolumn{1}{c}{ outcome } & \multicolumn{1}{c}{ predictor } & $\boldsymbol{b}$ & $\boldsymbol{t}$ \\
\hline mediator model & personal norm & descriptive social norm & .037 & .718 \\
& & neighbourhood identification & .089 & 1.907 \\
& identification $\times$ descriptive norm & .130 & $2.209^{*}$ \\
& self-identity & .332 & $7.175^{* * *}$ \\
& & control & .012 & .172 \\
DV model & attitude & .411 & $5.644^{* * *}$ \\
& \multirow{4}{*}{ intention } & injunctive social norm & .017 & .305 \\
& & personal norm & .154 & $3.032^{* *}$ \\
& descriptive social norm & .109 & $2.565^{*}$ \\
& neighbourhood identification & .032 & .840 \\
& identification $\times$ descriptive norm & -.035 & -.719 \\
& self-identity & .173 & $4.182^{* * *}$ \\
& & .210 & $3.848^{* * *}$ \\
& & control & .368 & $5.852^{* * *}$ \\
& attitude & .051 & -1.119 \\
\hline
\end{tabular}

\begin{tabular}{lccc}
\multicolumn{4}{c}{ bootstrap estimates at specific values of the moderator $(\mathbf{5 0 0 0}$ bootstrap samples) } \\
\hline \multicolumn{1}{c}{ identification } & indirect effect estimate & SE & $\boldsymbol{Z}$ \\
\hline S SD below mean & -.007 & .011 & -.595 \\
mean & .005 & .010 & .557 \\
1 SD above mean & .017 & .014 & 1.249 \\
\hline
\end{tabular}

Table 10: Moderated mediation involving descriptive norms, personal norms and neighbourhood identification, Study 2.

$* p<.05, * * p<.01, * * * p<.001$. 


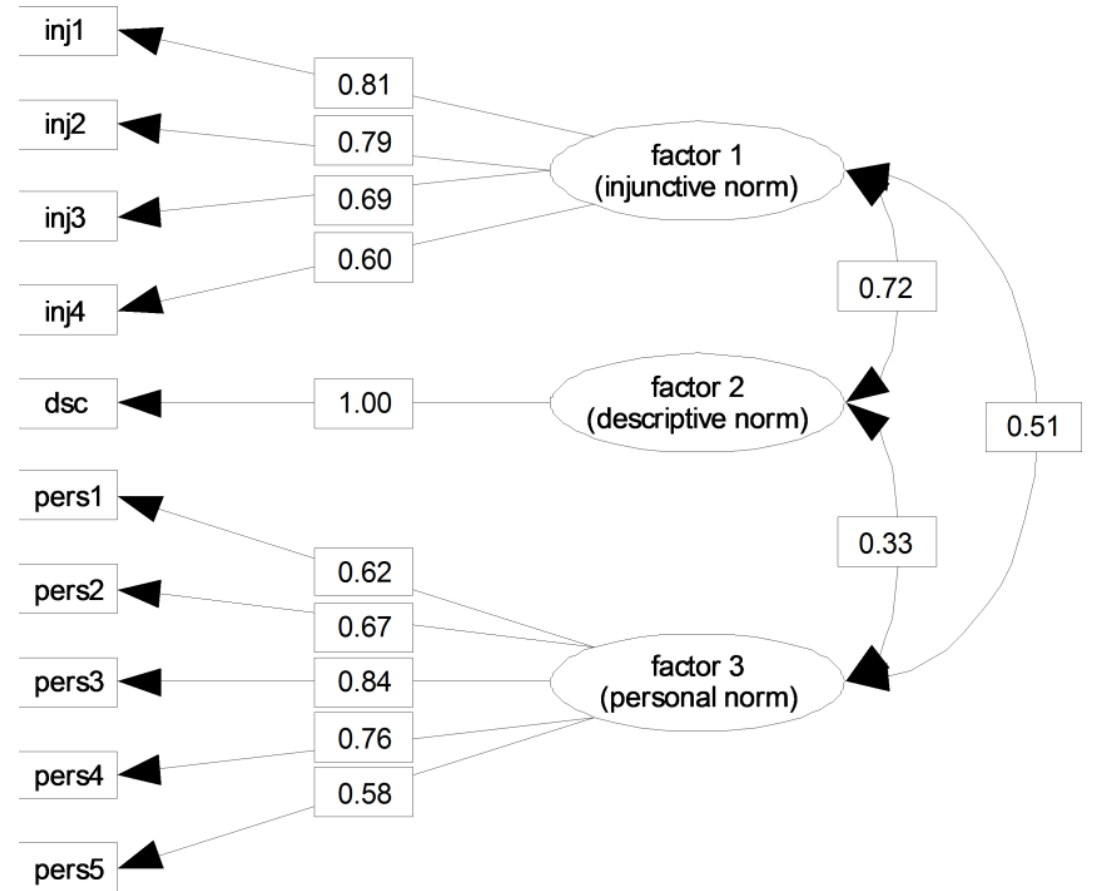

Figure 1: Confirmatory factor analysis on norm measures, Study 1.

Standardised estimated factor loadings are shown. All coefficients are significant $(p<.05)$. Errors are not displayed. 


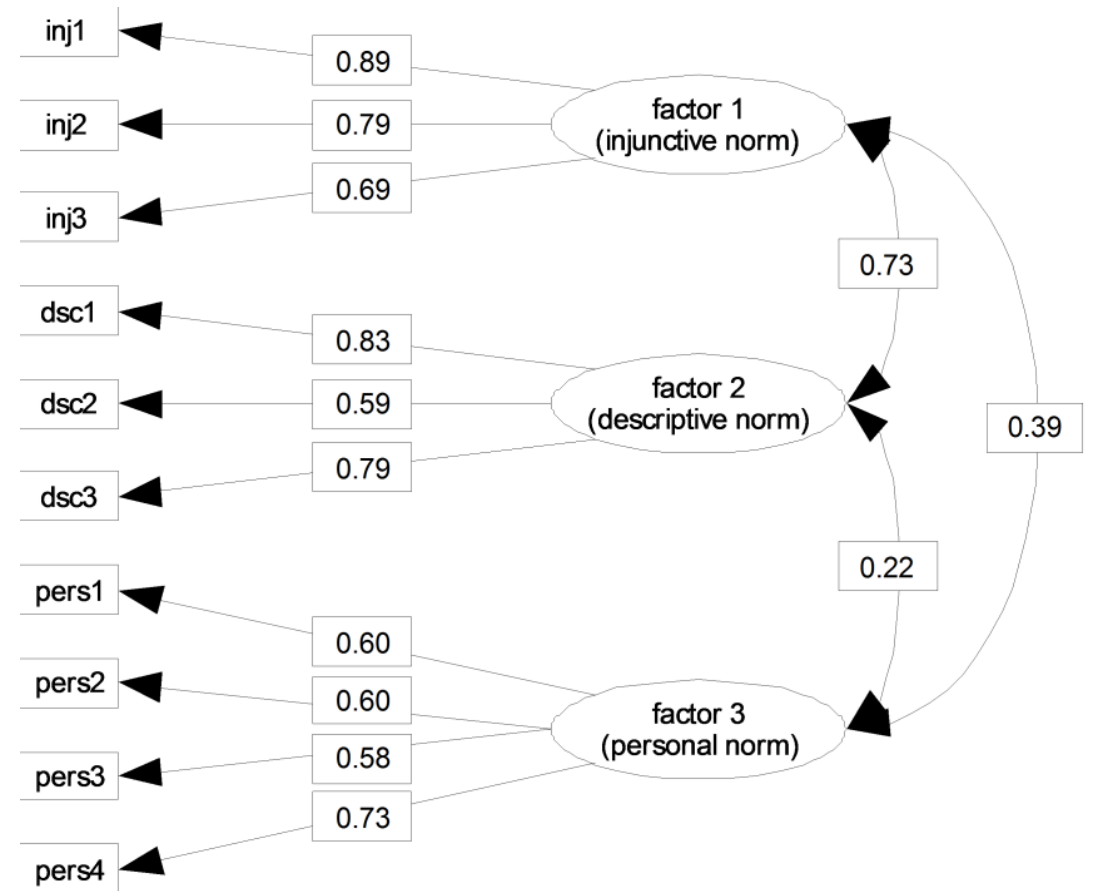

Figure 2: Confirmatory factor analysis on norm measures, Study 2. Standardised estimated factor loadings are shown. All coefficients are significant $(p<.05)$. Errors are not displayed. 